\title{
Assessing site-safeguard effectiveness and habitat preferences of Bar-headed Geese (Anser indicus) at their stopover sites within the Qinghai-Tibet Plateau using GPS/ GSM telemetry
}

Junjian Zhang 1,2, Yanbo Xie ${ }^{3}$, Laixing Li ${ }^{4}$, Nyambayar Batbayar ${ }^{5}$, Xueqin Deng ${ }^{1,2}$, Iderbat Damba ${ }^{1,6}$, Fanjuan Meng ${ }^{1}$, Lei Cao ${ }^{1,2^{*}}$ and Anthony David Fox ${ }^{7}$

\begin{abstract}
Background: The Bar-headed Goose (Anser indicus) breeds across the high plains and plateau of Central Asia and winters in the Qinghai-Tibet Plateau (QTP), the Yunnan-Guizhou Plateau and the Indian sub-continent. Of the two recognized discrete flyways of the Bar-headed Goose, the Eastern Tibetan Flyway (ETF) is the larger, comprising at least six migration routes. However, we remain ignorant about their migratory connectivity, habitat use and effectiveness of site-safeguard mechanisms set in place for the species.

Methods: We tracked 30 ETF Bar-headed Geese from Chinese and Mongolian breeding areas to their wintering grounds using GPS/GSM transmitters, to determine their migration routes and stopover staging patterns within the QTP, overlaying these upon GIS layers of protected area status and habitat type, to model their habitat selection.

Results: In total, 14 tagged Bar-headed Geese provided information on their entire autumn migration and 4 geese on their entire spring migration. Qinghai Lake marked birds overwintered in the QTP $(n=2)$, geese tagged in Mongolia wintered either in the QTP $(n=3)$ or in India/Bangladesh $(n=9)$, representing three of the migration routes within the ETF. In total, tagged birds staged at 79 different stopover sites within QTP in autumn and 23 in spring, of which $65 \%$ (autumn) and 59\% (spring) of all fixes fell within the boundaries of either National Nature Reserves (NNRs) or Important Birds Areas (IBAs) in the QTP. Bar-headed Geese predominantly occurred on four land-cover types: grassland (mostly by day), water bodies (at night), wetlands and bare substrates (salt flats, dry lake/river substrates and plough) with little change in proportion. Generalized linear mixed models comparing presence with pseudo-absence data suggested geese strongly selected for wetlands as staging habitat, avoiding bare substrates in spring.
\end{abstract}

Conclusions: Based on our limited observations of these tagged geese, this study is the first to show that the current designated National Nature Reserves in place in the staging areas within the QTP appear adequate to protect this increasing population. In addition, Hala Lake in Qinghai Province and adjacent areas used as initial QTP staging during

\footnotetext{
*Correspondence: leicao@rcees.ac.cn

1 State Key Laboratory of Urban and Regional Ecology, Research

Center for Eco-Environmental Sciences, Chinese Academy of Sciences, Beijing 100085, China

Full list of author information is available at the end of the article
}

(c) The Author(s) 2020. This article is licensed under a Creative Commons Attribution 4.0 International License, which permits use, sharing, adaptation, distribution and reproduction in any medium or format, as long as you give appropriate credit to the original author(s) and the source, provide a link to the Creative Commons licence, and indicate if changes were made. The images or other third party material in this article are included in the article's Creative Commons licence, unless indicated otherwise in a credit line to the material. If material is not included in the article's Creative Commons licence and your intended use is not permitted by statutory regulation or exceeds the permitted use, you will need to obtain permission directly from the copyright holder. To view a copy of this licence, visit http://creativeco mmons.org/licenses/by/4.0/. The Creative Commons Public Domain Dedication waiver (http://creativecommons.org/publicdomain/ zero/1.0/) applies to the data made available in this article, unless otherwise stated in a credit line to the data. 
autumn migration (currently outside of designated as NNRs/IBAs) are recommended for protection, based on their use by tagged birds from this study. Habitat modelling confirmed the importance of natural wetlands as feeding areas and safe areas of open water as roosting places.

Keywords: Anser indicus, Bar-headed goose, Habitat use, Habitat selection, Important bird area, National nature reserve

\section{Background}

The Bar-headed Goose (Anser indicus) has increased greatly in abundance since the 1990 s, reaching an estimated world population of 97,000-118,000, distributed across a fragmented breeding range throughout the high plains and plateaux of Central Asia (Liu et al. 2017; Fox and Leafloor 2018). Previous telemetry studies have demonstrated the existence of two major flyways of this species in Central Asia (Additional file 1: Fig. S1; Prosser et al. 2009, 2011; Bourouiba et al. 2010; Hao et al. 2010; Köppen et al. 2010; Zhang et al. 2011b; Newman et al. 2012). These can be summarized as follows. The first flyway is the Western Tibetan Flyway, breeding in SE Kyrgyzstan, Kazakhstan and the NW Xinjiang Uygur Autonomous Region in China. These birds winter in Pakistan and the Western Indian subcontinent and comprise more than 30,000 birds, based on wintering counts, including 1800-5000 in Pakistan (Li et al. 2009; Van der Ven et al. 2010), and 19,000-40,000 at Pong Dam (Takekawa et al. 2017), the major site for the species on the Indian subcontinent.

Birds from the second flyway, the Eastern Tibetan Flyway (hereafter ETF), breed from Western Mongolia, the SE Xinjiang Uygur Autonomous Region, China to the Qinghai-Tibet Plateau, China (hereafter QTP). These birds are thought to winter mainly in the southern QTP and the Yunnan-Guizhou Plateau in China, throughout the Central and Eastern Indian subcontinent, and in Myanmar. This population is estimated to number more than 80,000 birds based on wintering counts, including 67,000 along the Yarlung Zangbo River and adjacent area (Liu et al. 2017), 5300-7200 on the Yunnan-Guizhou Plateau (Yang 2005; Yang and Zhang 2014) and 3500-5800 in Nepal/Bangladesh/Myanmar (Li et al. 2009; Takekawa et al. 2009; Van der Ven et al. 2010). Unknown numbers also winter in East India.

Movements of the Bar-headed Goose were closely studied after an outbreak of highly pathogenic avian influenza (HPAI) H5N1, which killed more than 3000 geese in Qinghai Lake (Chen et al. 2006). These studies identified the importance of tracking their annual movements, because such an increasing and expanding species, showing diverse migration routes and which often uses agriculture areas during staging and in winter, has the potential to rapidly transmit HPAI along its migration routes (Liu et al. 2010).

The ETF includes more than $70 \%$ of the individuals in the global population, and most previous studies of this flyway have focused on their breeding and wintering grounds. For instance, breeding habitat use and selection of the Bar-headed Geese has been studied at Qinghai Lake in China (Liu et al. 2008; Cui et al. 2011; Zhang et al. 2011b) and Hangcuo Lake (Zhang et al. 2011a), westcentral Mongolia (Batbayar et al. 2014) and Ladakh in India (Prins and van Wieren 2004). Similar studies have taken place on the wintering grounds, including at Caohai Lake (Yang et al. 2012, 2013), Lashihai Lake (Yan et al. 2014) and Yamdrok Lake (Zhang et al. 2016) in China, and Keoladeo National Park in India (Middleton 1992). These studies are important, because Bar-headed Geese distribute two-thirds of their year between the breeding and wintering sites (Takekawa et al. 2017). However, few studies have attempted to identify crucial stopover sites used during migration, especially in the ETF (Hao et al. 2010; Zhang et al. 2011b; Prosser et al. 2011). Although the migration period comprises only one-third of the annual cycle of the geese, energy acquisition to fuel migration can be critical and it is known that migration mortality can exceed $85 \%$ of overall annual deaths in some species (Ydenberg 2017). Hence, an understanding of stopover sites used by Bar-headed Geese is fundamental to our ability to effectively conserve the species and understand the potential for disease transmission.

The Bar-headed Goose is famous for its trans-Himalayan migration and studies have demonstrated its physiological adaptations for flying at altitudes over $6000 \mathrm{~m}$ where oxygen pressure is very low (Hawkes et al. 2011, 2013, 2017; Bishop et al. 2015). Due to the lower air density, Bar-headed Geese flying at such altitudes, suffer not only severe hypoxia, but increase wing beat rates compared to those at sea level to gain the same lift effect, doubling the power requirement (Bishop et al. 2015). Bearing this in mind, however, given the importance of their stopover sites within QTP to provide the necessary energy to cross the QTP, complete their migration and breed successfully, we know lamentably little about the precise Bar-headed Goose staging areas, habitat preferences and their conservation status there. 
Here, we attempt to define Bar-headed Goose habitat selection (as distinct from simple habitat use; Jones 2001) to understand how the birds might be showing behavioral responses to changes in habitat conditions, which potentially affect the survival and adaptability of individuals (Block and Brennan 1993). Only by revealing habitat selection patterns, can we fully understand the spatial and temporal distribution of the Bar-headed Geese we follow. Based on results from a previous study, which used geographical information to model habitat selection in ETF breeding areas (Zheng et al. 2018), we identified six key parameters in modelling habitat selection, including land cover (each class is treated as a separate variable), elevation, slope, aspect, distance to river/ lake and road.

In this investigation, we applied further telemetry devices to samples of birds on their key breeding areas in China and Mongolia, to extend earlier studies of this species, with the specific aim of identifying key staging areas throughout the migratory life cycle of these birds. Most importantly, we specifically compare the areas used by tagged Bar-headed Geese to assess the effectiveness of currently designated areas in the QTP to protect key staging areas during migration for the species and to determine their habitat use and selection at these areas.

\section{Methods}

\section{Capture of individuals and transmitter attachment}

In June 2016, three Bar-headed Geese (of unknown age and sex) rescued and rehabilitated by the Qinghai Lake National Nature Reserve Rescue Center were fitted with neck collar-mounted GPS/GSM loggers (weight $40 \mathrm{~g}$, Hunan Global Messenger Technology Co., China) and released at Qinghai Lake $\left(37.07{ }^{\circ} \mathrm{N}, 99.82{ }^{\circ} \mathrm{E}\right.$, China). The signal was lost from one of the birds during autumn migration, but the two other geese completed their autumn migrations in 2016.

In July 2018, 27 individuals (adult, unknown sex) were rounded up during the flightless moult period and captured at Terkhiin Tsagaan Lake $\left(48.15^{\circ} \mathrm{N}, 99.59^{\circ} \mathrm{E}\right.$, Mongolia) and Bayan Lake $\left(49.94{ }^{\circ} \mathrm{N}, 93.90^{\circ} \mathrm{E}\right.$, Mongolia), and fitted with backpack-mounted GPS/GSM loggers (weight 27.5 g, Ornithology and Telemetry Applications, UAB). Of these marked birds from Mongolia, 13 geese provided complete data on the full autumn migration in 2018 (among them, two geese accompanied each other on migration), and four geese on the full spring migration in 2019. Although we cannot eliminate the possibility that the fitted devices affected the behaviour and ecology of these individuals, the loggers constituted much less than $3 \%$ to individual total body mass above which it is considered this may more likely occur (Millspaugh and Marzluff 2001; Bodey et al. 2018).
Devices attached in 2016 and 2018 were set to record the GPS locations at $2 \mathrm{~h}$ and $10 \mathrm{~min}$ intervals throughout the research project, respectively. Some individuals were tracked for more than one year and two individuals migrated together. To avoid pseudo-replication, only the first spring and autumn migration tracks were selected from each individual, and only one bird from the individuals that accompanied each other on migration were selected (Additional file 2: Table S1).

\section{Identifying stopover sites}

We applied the method of Wang et al. (2018) to segment movement tracks into "fly" and "non-fly", then we plotted locations in Google Earth to visualize movements, pinpoint arrival and departure dates at sites, and evaluate where birds were wintering, summering or stopping (Page et al. 2014). We defined stopover sites as locations where a bird did not move $>30 \mathrm{~km}$ over a $48 \mathrm{~h}$ period (Kölzsch et al. 2016). The staging areas, which include at least two stopover sites with distance less than $30 \mathrm{~km}$ from each other, were identified and categorized by manual checking on maps and Google Earth according to duration and location (Chen et al. 2016). In order to exclude the moving positional fixes during stopovers, we only retained the GPS locations where the velocity between adjacent points was less than $1 \mathrm{~km} / \mathrm{h}$.

\section{Conservation status of stopovers within the Qinghai-Tibet Plateau}

We attempted to assess the effectiveness of the current extent of designated Important Bird and Biodiversity Areas (IBAs), and National Nature Reserves of China (NNRs) for the protection of stopover sites in the QTP used by these tagged Bar-headed Geese. We downloaded China's IBA (BirdLife International 2020) and NNR boundary information with permissions (https://www. resdc.cn/data.aspx?DATAID $=272$ ). We then overlaid all stopover sites in the QTP used by tagged Bar-headed Geese in our study through ArcMap 10.6 to identify which GPS fixes were located within IBA and NNR boundaries.

\section{Environmental variables}

To characterize the landcover used by tracked geese, we used the "FROM-GLC 2017v1" land cover dataset (resolution $10 \mathrm{~m} \times 10 \mathrm{~m}$ ) created by the Department of Earth System Science, Tsinghua University (Gong et al. 2019). The dataset is based upon 10 land cover classification types, namely artificial surfaces, bare substrate, cropland, forest, grassland, permanent snow/ice, shrubland, tundra, wetland and water bodies. Wetland includes marshland and mudflats with natural and semi-natural aquatic or regularly flooded vegetation; water bodies include 
natural and artificial waterbodies, such as lake, river and reservoir/pond (for detailed definitions of land cover categories, see Gong et al. 2013). We assigned each GPS location within the stopover sites in the QTP to a specific land-use type defined by the land cover data using R 3.6.0 ( $\mathrm{R}$ Core Team 2019). GPS fixes were assigned to day or night based on local sunrise and sunset times calculated by "solartime" package (v0.0.1; Wutzler 2018).

We used elevation data measured from SRTM3-DEM dataset (resolution $30 \mathrm{~m} \times 30 \mathrm{~m}$ ) created by NASA and NIMA, and calculated slope and aspect (defined as a parameter value running from 0 to 360 , starting from the West and increasing clockwise) for each GPS fix using ArcMap 10.6. Finally, we calculated the shortest distance of each GPS fixes in stopovers to roads (downloaded from https://www.worldclim.org/) and rivers (downloaded from https://download.csdn.net/download/weixi n_38779546/10613773), respectively.

\section{Resource selection modeling}

We used generalized linear mixed models (GLMMs) with a binomial error structure to evaluate stopover resource selection during autumn and spring migration respectively, with use/availability as response variable and environment variables as explanatory variables (Meng et al. 2020). We diluted GPS fixes to hourly intervals to reduce the potential for autocorrelation (Signer et al. 2019).

Availability data (i.e., pseudo-absence data) at each stopover site were generated by creating $100 \%$ minimum convex polygons (MCPs) based on each set of positions for tagged individuals. We extended these outwards by $11.3 \mathrm{~km}$ (the average maximum hourly displacement for all individuals at all stopover sites) in all directions around the MCPs to represent the area potentially available to each of the staging birds. We then randomly selected locations from the extended MCP for each stopover site as pseudo-absence data, generating 20 pseudoabsence points for each positional fix to gain stable and unbiased parameter estimates (Northrup et al. 2013).

Rare land cover types $(<5 \%$ of total land use by either use or availability data points) were excluded (namely artificial surfaces, cropland, forest, shrubland, tundra and snow/ice), to escape model convergence problems likely below such levels (Altman et al. 2004). We rescaled variables using the "scale" function in "base" package in R, following the method of Becker and Chambers (1984) to estimate the effect size of explanatory variables.

We used the "dredge" function in "MuMIn" package (v1.43.10; Bartoń 2019) in $\mathrm{R}$ to develop our resource selection model using model weights derived from AICc criteria. The cross-prediction accuracy of our resource selection model was tested by estimating the area under the receiver operating characteristic (ROC) curve (AUC).
AUC values can range between 0 and 1, where 0.5 indicates predictions no better than chance, 1 indicates perfect discrimination, with values above 0.7 being generally accepted as indicating reasonable predictions (Hosmer et al. 2013). Finally, we applied odds ratios to evaluate effect size of the variables (Szumilas 2010).

\section{Results \\ Tracking results}

A total of 17 geese in autumn, and 8 geese in spring began migration with functioning transmitters, however, due to mortalities and transmitter malfunction, we were only able to obtain information on the full migration for 14 and 4 geese during autumn and spring migration, respectively. Based on the complete migration data from 2016 and 2018 combined, the tagged birds followed three different migration routes. Birds marked at Qinghai Lake overwintered in the Shigatse Prefecture of Tibet Autonomous Region (TAR) $(n=2)$, whereas geese marked in Mongolia either wintered in the Shigatse Prefecture $(n=3)$ or continued down into India $(n=7)$ or Bangladesh $(n=2)$ to winter (Fig. 1). In addition, tracked geese (another three geese in autumn and another four in spring that started but did not complete migration) staged at 79 different stopover sites in autumn and 23 in spring within the QTP (Fig. 1; Additional file 2: Tables S2, S3). The cumulative time that all birds spent at stopover sites within the QTP totaled $1445 \mathrm{~h}$, which constituted $86.7 \%$ of the entire stopover duration (1667 h).

Tagged Bar-headed Geese that summered in Mongolia and wintered in India/Bangladesh, arrived in the QTP during autumn migration on average on September 8 ( \pm 7 days standard deviation; $n=9$ individuals) and left the QTP on November 19 ( \pm 13 days). In spring, they arrived in the QTP from India or Bangladesh on average on March 15 ( \pm 6 days; $n=6$ ) and left on April 25 ( \pm 6 days; $n=3$; another three geese started but did not complete migration). Bar-headed Geese spent an average of $72.3 \pm 17.3$ days $(n=9)$ and $44.3 \pm 7.1$ days $(n=3)$ in the QTP during autumn and spring migration respectively.

\section{Conservation status of stopover sites}

Data from the goose-borne loggers generated 123,539 non-moving GPS fixes in autumn and 51,282 in spring at stopover sites within the QTP. Of these, 59\% and $53 \%$ of GPS fixes in autumn and spring respectively fell within NNRs, while $27 \%$ and $23 \%$ of GPS fixes were from within IBAs. Overall, $65 \%$ and $59 \%$ of GPS fixes were from within NNRs/IBAs (Figs. 2, 3; Additional file 2: Table S4). In all, we found 12 important staging areas with at least two stopover sites (Table 1). Among 


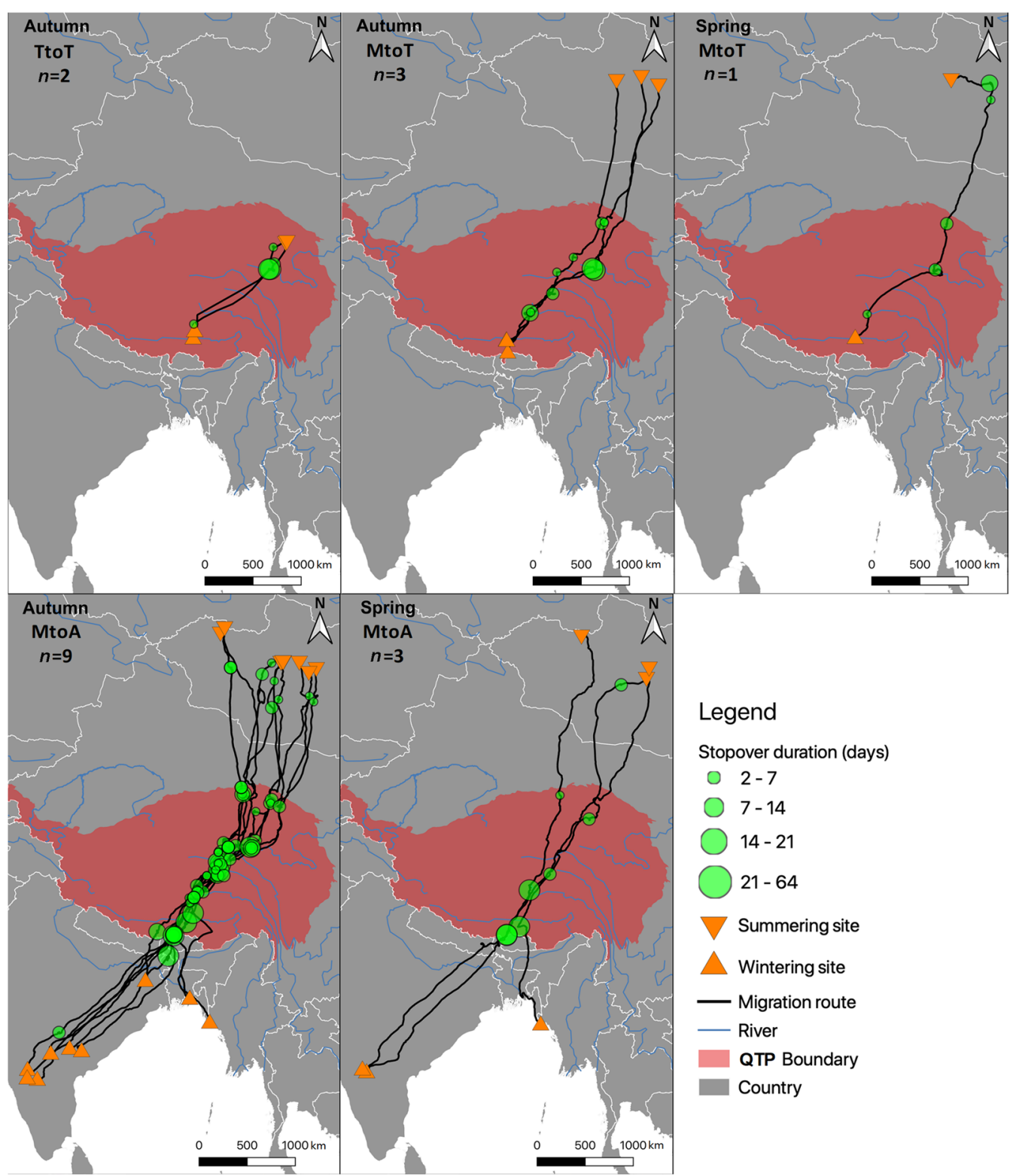

Fig. 1 Autumn and spring individual migration routes (black lines) and stopover sites (green circles) of Bar-headed Geese (Anser indicus) derived from GPS/GSM telemetry devices deployed on birds tracked in 2016 and 2018/2019. The shaded red region shows the Qinghai-Tibet Plateau. TtoT: Qinghai Lake - Shigatse Prefecture routes; MtoT, Mongolia - Shigatse Prefecture routes; MtoA, Mongolia-India/Bangladesh routes. Sample sizes are indicated by $n$ (number of individuals finishing migration)

these, there were three areas containing at least three stopovers, which fell outside existing NNRs/IBAs designation (Fig. 2). These were: (1) Shule River, Qinghai Province, $N_{\mathrm{s}}=6\left(N_{\mathrm{s}}\right.$ in each case represents the number of stopovers; No. 2 in Table 1; close to Hala Lake); (2) Dangqu River, TAR, $N_{\mathrm{s}}=3$ (No. 11; outside of the Se Lin Cuo NNR and near downtown Dangxiong county);
(3) Duoqingcuo Lake, TAR, $N_{\mathrm{s}}=11$ (No. 12; a national wetland park and close to the highway).

\section{Habitat use and selection in stopover sites}

Habitat types used by the Bar-headed Geese were predominantly natural ecosystems: $31 \%$ grassland, $29 \%$ bare substrate (including dry salt flats, bare herbaceous croplands and dry lake/river bottoms; Gong et al. 2013), 26\% water bodies and $11 \%$ wetlands. Habitat types used by 

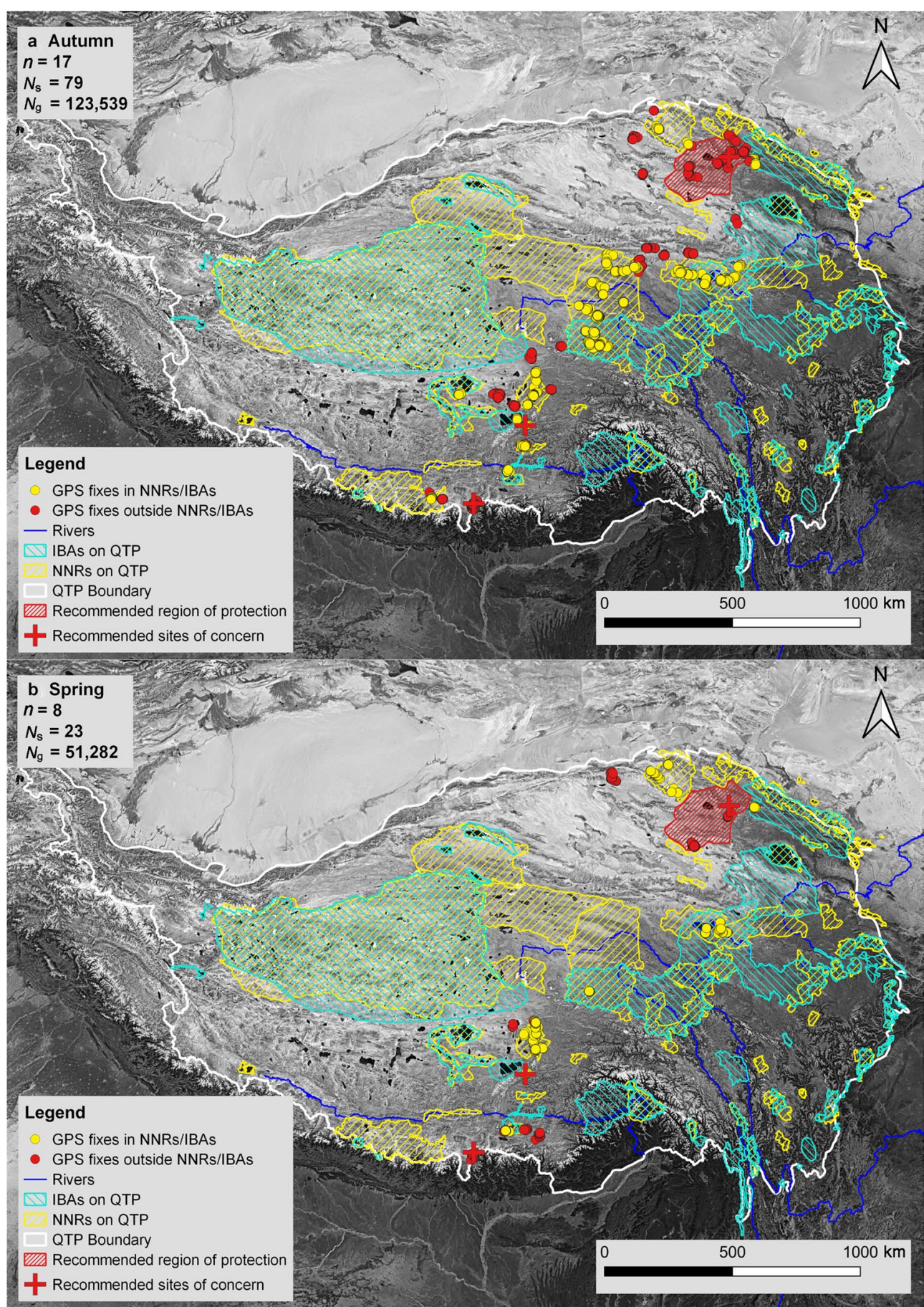

Fig. 2 GPS fixes of stopover sites within the QTP for tagged Bar-headed Geese during autumn and spring migration in 2016 and 2018/2019. a stopovers during autumn migration; b stopovers during spring migration. NNRs: National Nature Reserves of China; IBAs: Important Bird and Biodiversity Areas; QTP, the Qinghai-Tibet Plateau. Sample sizes are indicated by $n$ (number of instrumented individuals generating the data), $N_{s}$ (number of stopovers within QTP) and $N_{g}$ (total number of GPS fixes per category). The explanations apply also to Figs. 3, 4 


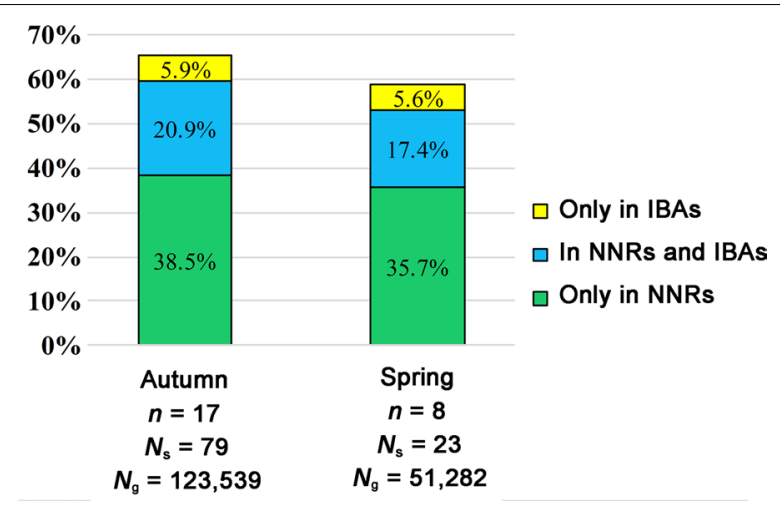

Fig. 3 Conservation status of Bar-headed Geese stopovers within the Qinghai-Tibet Plateau during autumn (totally 63.3\%) and spring (58.7\%) migration in 2016 and 2018/2019 geese differed between day (the majority on grassland, $47 \%$ in autumn and $33 \%$ in spring) and night (when the majority were using waterbodies, $33 \%$ in autumn and $41 \%$ in spring), but were similar during autumn and spring migration (Fig. 4).

Comparing GLMMs results, the best fit models for predicting spring and autumn Bar-headed Goose stopover sites within the QTP were based on the same nine parameters. These included the four habitat types, as well as slope, aspect, elevation, distance to roads and rivers (autumn: weight $=1.000, \mathrm{AUC}=0.80 ;$ spring: weight $=1.000$, AUC $=0.83$; Table 2). All these parameters are significant $(p<0.001$; Fig. 5). Among habitat types, Bar-headed Geese tended to strongly select wetlands $\left(\beta_{\text {autumn }}=1.94, \beta_{\text {spring }}=2.03\right)$, slightly select water bodies $\left(\beta_{\text {autumn }}=0.62, \beta_{\text {spring }}=0.80\right)$, slightly avoided to select grassland $\left(\beta_{\text {autumn }}=-0.95, \quad \beta_{\text {spring }}=-1.05\right)$, and were least likely to select bare substrates in spring $\left(\beta_{\text {spring }}=-2.01\right)$. Among terrain variables, geese tended to select stopovers facing south $\left(\beta_{\text {autumn }}=0.30\right.$,

Table 1 Important staging areas used by tagged Bar-headed Geese (Anser indicus) migrating in the Eastern Tibetan Flyway in 2016 and 2018/2019

\begin{tabular}{|c|c|c|c|c|c|c|c|}
\hline No & Stopover sites \& coordinates & Season & $\begin{array}{l}\text { No. } \\
\text { of stopovers }\end{array}$ & Date range & $\begin{array}{l}\text { Length of stay } \\
\text { (range in days) }\end{array}$ & Protection status & $\begin{array}{l}\text { IBA } \\
\text { sites } \\
\text { (Y/N) }\end{array}$ \\
\hline \multirow[t]{2}{*}{1} & \multirow{2}{*}{$\begin{array}{l}\text { River of Subei Mongolian Autono- } \\
\text { mous County, Gansu Province, } \\
\text { China }\left(95.829^{\circ} \mathrm{N}, 39.105^{\circ} \mathrm{E}\right)\end{array}$} & Autumn & 3 & $9 / 2-9 / 21$ & $4-16$ & \multirow[t]{2}{*}{ Yan Chi Wan National Nature Reserve } & \multirow[t]{2}{*}{ N } \\
\hline & & Spring & 1 & $4 / 25-6 / 4$ & 41 & & \\
\hline \multirow[t]{2}{*}{2} & \multirow{2}{*}{$\begin{array}{l}\text { Shule River, Tianjun County, Qinghai } \\
\text { Province, China ( } 98.321^{\circ} \mathrm{N}, 38.297 \\
\left.{ }^{\circ} \mathrm{E}\right)\end{array}$} & Autumn & 5 & $9 / 2-9 / 29$ & $3-11$ & \multirow[t]{2}{*}{ None } & \multirow[t]{2}{*}{$\mathrm{N}$} \\
\hline & & Spring & 1 & $5 / 13-5 / 17$ & 5 & & \\
\hline \multirow[t]{2}{*}{3} & \multirow{2}{*}{$\begin{array}{l}\text { Lake of Madoi County, Qinghai Prov- } \\
\text { ince, China }\left(97.773^{\circ} \mathrm{N}, 34.848^{\circ} \mathrm{E}\right)\end{array}$} & Autumn & 5 & $8 / 27-11 / 9$ & $8-63$ & \multirow{2}{*}{$\begin{array}{l}\text { San Jiang Yuan National Nature } \\
\text { Reserve }\end{array}$} & \multirow[t]{2}{*}{ Y } \\
\hline & & Spring & 2 & $4 / 12-5 / 11$ & $11-16$ & & \\
\hline 4 & $\begin{array}{l}\text { River of Qumarleb County, Qinghai } \\
\text { Province, China ( } 96.654^{\circ} \mathrm{N}, 35.083 \\
\left.{ }^{\circ} \mathrm{E}\right)\end{array}$ & Autumn & 5 & $9 / 18-10 / 24$ & $4-23$ & $\begin{array}{l}\text { San Jiang Yuan National Nature } \\
\text { Reserve }\end{array}$ & N \\
\hline 5 & $\begin{array}{l}\text { River of Qumarleb County, Qinghai } \\
\text { Province, China ( } 95.141^{\circ} \mathrm{N}, 35.265 \\
\left.{ }^{\circ} \mathrm{E}\right)\end{array}$ & Autumn & 2 & $9 / 1-11 / 1$ & $3-9$ & $\begin{array}{l}\text { San Jiang Yuan National Nature } \\
\text { Reserve }\end{array}$ & N \\
\hline 6 & $\begin{array}{l}\text { River of Qumarleb County, Qinghai } \\
\text { Province, China }\left(93.707^{\circ} \mathrm{N}, 34.67^{\circ} \mathrm{E}\right)\end{array}$ & Autumn & 4 & $9 / 11-10 / 14$ & $3-20$ & $\begin{array}{l}\text { San Jiang Yuan National Nature } \\
\text { Reserve }\end{array}$ & N \\
\hline 7 & $\begin{array}{l}\text { River of Zhidoi County, Qinghai Prov- } \\
\text { ince, China }\left(93.581^{\circ} \mathrm{N}, 33.86^{\circ} \mathrm{E}\right)\end{array}$ & Autumn & 6 & $9 / 2-11 / 15$ & $5-21$ & $\begin{array}{l}\text { San Jiang Yuan National Nature } \\
\text { Reserve }\end{array}$ & N \\
\hline \multirow[t]{2}{*}{8} & \multirow{2}{*}{$\begin{array}{l}\text { Lake of Zadoi County, Qinghai Prov- } \\
\text { ince, China }\left(93.497^{\circ} \mathrm{N}, 33.025^{\circ} \mathrm{E}\right)\end{array}$} & Autumn & 7 & $9 / 2-10 / 22$ & $4-27$ & \multirow{2}{*}{$\begin{array}{l}\text { San Jiang Yuan National Nature } \\
\text { Reserve }\end{array}$} & \multirow[t]{2}{*}{ Y } \\
\hline & & Spring & 1 & $4 / 17-4 / 27$ & 11 & & \\
\hline \multirow[t]{2}{*}{9} & \multirow{2}{*}{$\begin{array}{l}\text { Lake of Ando County, Tibet, China } \\
\quad\left(91.491^{\circ} \mathrm{N}, 31.992^{\circ} \mathrm{E}\right)\end{array}$} & Autumn & 3 & $10 / 1-10 / 24$ & $2-8$ & \multirow[t]{2}{*}{ Se Lin Cuo National Nature Reserve } & \multirow[t]{2}{*}{$\mathrm{N}$} \\
\hline & & Spring & 2 & $4 / 3-4 / 24$ & $2-22$ & & \\
\hline \multirow[t]{2}{*}{10} & \multirow{2}{*}{$\begin{array}{l}\text { Lake of Naqu County, Tibet, China } \\
\quad\left(91.506^{\circ} \mathrm{N}, 31.424^{\circ} \mathrm{E}\right)\end{array}$} & Autumn & 5 & $10 / 9-10 / 31$ & $2-20$ & \multirow[t]{2}{*}{ Se Lin Cuo National Nature Reserve } & \multirow[t]{2}{*}{ N } \\
\hline & & Spring & 2 & $4 / 5-4 / 15$ & $3-5$ & & \\
\hline \multirow[t]{2}{*}{11} & \multirow{2}{*}{$\begin{array}{l}\text { Dangqu River, Damxung County, } \\
\text { Tibet, China }\left(91.165^{\circ} \mathrm{N}, 30.525^{\circ} \mathrm{E}\right)\end{array}$} & Autumn & 2 & $10 / 26-11 / 14$ & $4-13$ & \multirow[t]{2}{*}{ None } & \multirow[t]{2}{*}{ N } \\
\hline & & Spring & 1 & $4 / 13-4 / 21$ & 8 & & \\
\hline \multirow[t]{2}{*}{12} & \multirow{2}{*}{$\begin{array}{l}\text { Duoqingcuo Lake, Yadong County, } \\
\left.\text { Tibet, China ( } 89.357^{\circ} \mathrm{N}, 28.139^{\circ} \mathrm{E}\right)\end{array}$} & Autumn & 8 & $10 / 21-11 / 19$ & $8-24$ & \multirow[t]{2}{*}{ None } & \multirow[t]{2}{*}{ N } \\
\hline & & Spring & 3 & $3 / 6-4 / 12$ & $20-26$ & & \\
\hline
\end{tabular}




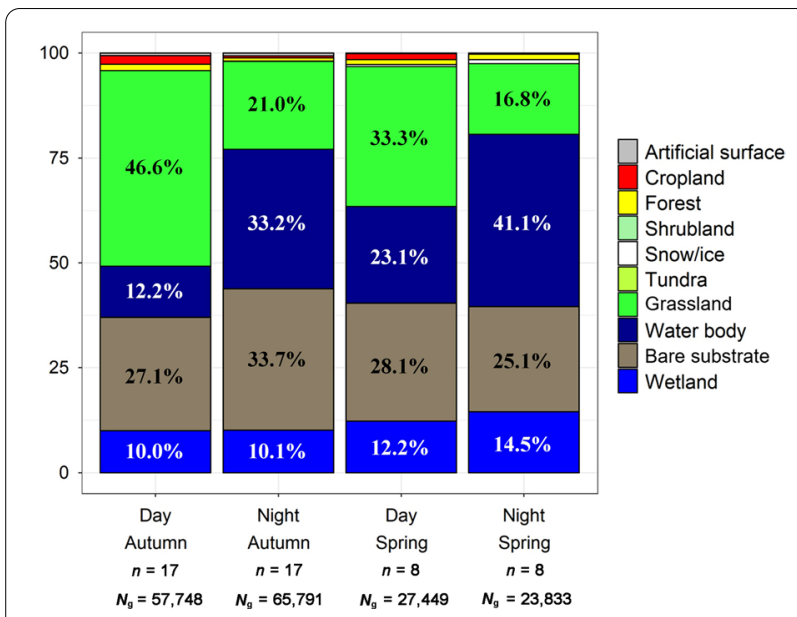

Fig. 4 Percentage habitat use of Bar-headed Geese during stopovers within the Qinghai-Tibet Plateau during autumn and spring migration in 2016 and 2018/2019 respectively, based on positional fixes from deployed GPS loggers overlaid on land-cover maps of the world (see Methods)

Table 2 Model selection results for the top five stopover habitat selection analysis models for the Bar-headed Geese during autumn and spring migration in 2016 and $2018 / 2019$ respectively

\begin{tabular}{|c|c|c|c|c|c|}
\hline Season & ID & Model structure $^{a}$ & df & $\triangle \mathrm{AIC}^{\mathrm{b}}$ & Weight \\
\hline \multirow[t]{5}{*}{ Autumn } & 1 & $\mathrm{LC}+\mathrm{ROA}+\mathrm{RIV}+\mathrm{ELV}+\mathrm{SLP}+\mathrm{ASP}$ & 12 & 0.0 & 1 \\
\hline & 2 & $\mathrm{LC}+\mathrm{ROA}+\mathrm{RIV}+\mathrm{SLP}+\mathrm{ASP}$ & 11 & 206.6 & 0 \\
\hline & 3 & $L C+R I V+E L V+S L P+A S P$ & 11 & 397.4 & 0 \\
\hline & 4 & $L C+R O A+E L V+S L P+A S P$ & 11 & 567.8 & 0 \\
\hline & 5 & $L C+R I V+S L P+A S P$ & 10 & 607.4 & 0 \\
\hline \multirow[t]{5}{*}{ Spring } & 1 & $\mathrm{LC}+\mathrm{ROA}+\mathrm{RIV}+\mathrm{ELV}+\mathrm{SLP}+\mathrm{ASP}$ & 12 & 0.0 & 1 \\
\hline & 2 & $\mathrm{LC}+\mathrm{RIV}+\mathrm{ELV}+\mathrm{SLP}+\mathrm{ASP}$ & 11 & 110.9 & 0 \\
\hline & 3 & $L C+R O A+R I V+S L P+A S P$ & 11 & 342.6 & 0 \\
\hline & 4 & $L C+R O A+E L V+S L P+A S P$ & 11 & 437.8 & 0 \\
\hline & 5 & $L C+E L V+S L P+A S P$ & 10 & 446.4 & 0 \\
\hline
\end{tabular}

a LC, land cover; ROA, distance to roads; RIV, distance to river; ELV, elevation; SLP, slope; ASP, aspect

b $\triangle \mathrm{AIC}$, the difference between the current model $\mathrm{AIC}$ value and the minimum AIC value

$\left.\beta_{\text {spring }}=0.32\right)$, with low elevation $\quad\left(\beta_{\text {autumn }}=-0.12\right.$, $\left.\beta_{\text {spring }}=-0.31\right)$ and slope $\left(\beta_{\text {autumn }}=-2.00, \beta_{\text {spring }}=-1.17\right)$ both during autumn and spring migration. Among other variables, geese tended to select stopover sites, which were away from roads $\left(\beta_{\text {autumn }}=0.16, \beta_{\text {spring }}=0.29\right)$ and close to rivers $\left(\beta_{\text {autumn }}=-0.22, \beta_{\text {spring }}=-0.43\right)$ both during autumn and spring migration (see Additional file 2: Tables S5, S6 for full model details).

\section{Discussion}

The results of this tracking study clearly show that three NRRs: Yan Chi Wan (Gansu Province), San Jiang Yuan (Qinghai Province), and Se Li Cuo (TAR) are of critical importance to Bar-headed Geese in the ETF during both autumn and spring migration. In particular, the importance of rivers in Yan Chi Wan (No. 1 in Table 1) and San Jiang Yuan NNRs (No. 5, 6) were not previously known. Overall, 65\% of autumn GPS fixes were from within NNRs/IBAs and 59\% in spring. Our studies confirmed the importance of Hala Lake (close to Shule River, No. 2), San Jiang Yuan NNR (No. 3, 4) and Se Lin Cuo NNR (No. 7-10) indentified by tagged Bar-headed Geese in previous studies (Hao et al. 2010; Zhang et al. 2011b; Prosser et al. 2011). Nevertheless, our tracking data found additional areas frequently used by tracked geese, which are not currently designated as NNRs/IBAs. Of these, the most important appear to be the Shule River, Qinghai Province, the Dangqu River, TAR and Duoqingcuo Lake, TAR, all of which are recommended for ground survey during the migration season based on their prolonged use (3-26 days) by tagged birds from this study.

We would also recommend surveying the suitability of adding Hala Lake and adjacent areas $\left(97.60^{\circ} \mathrm{N}, 38.30^{\circ} \mathrm{E}\right.$; Fig. 2) to the protected area network for this species, as part of the ecological redline for the region. This is part of the NE edge of the QTP which represents the first staging area encountered and used by geese during autumn migration, yet very few of our tracked birds used areas inside the current protected area boundaries, despite the importance of the position of this area in the overall migration network (Xu et al. 2020).

The ETF represents the larger of the two flyways of the Bar-headed Goose, supporting more than 80,000 individuals. Within this flyway, it is thought that there at least six migration routes (Additional file 1). These are: (1) Mongolia-Yarlung Zangbo River, China; (2) Mongolia-East Indian sub-continent; (3) Qinghai Lake-Yarlung Zangbo River, China; (4) Qinghai Lake-Yunnan-Guizhou Plateau, China (Zhang et al. 2011b); (5) Xinjiang-Yarlung Zangbo River, China (Liu et al. 2010); (6) Yarlung Zangbo River, China-Central Indian sub-continent (Newman et al. 2012). Our study only covered the first three of these migration routes, so there remains three other migration routes that are poorly studied, not to mention those used by geese from the Western Tibetan Flyway (Köppen et al. 2010).

After pooling the data from tracked Bar-headed Geese (both from this and other studies) which completed autumn migration and were captured in Mongolia $(n=24)$ and Qinghai Lake, China $(n=40), 38$ of these individuals wintered in the QTP, 25 in Indian sub-continent, and only one on the Yunnan-Guizhou Plateau (Tian 

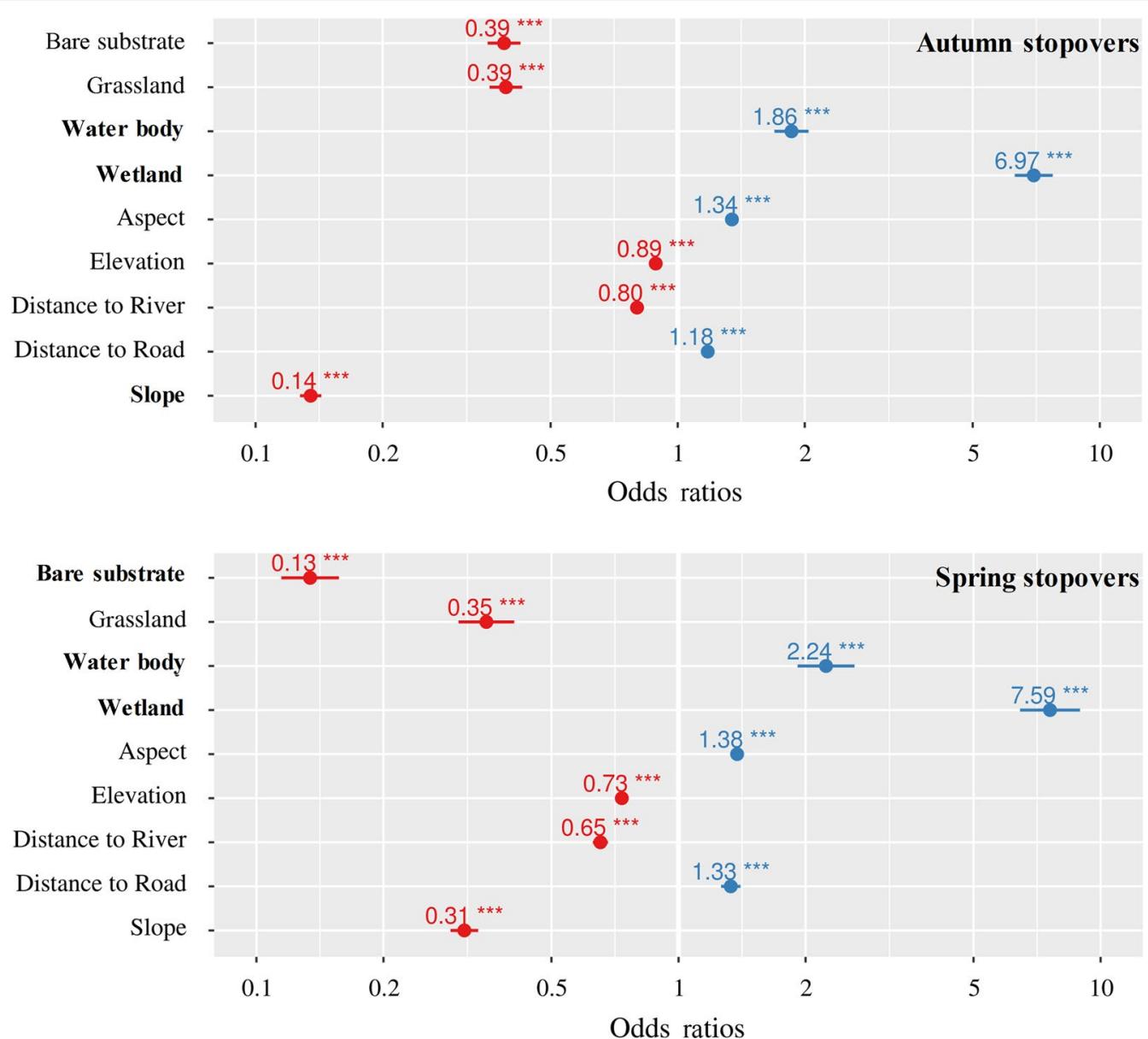

Fig. 5 Odds ratios of fixed effects in highest-ranked generalized mixed-effect model for autumn and spring stopovers in 2016 and 2018/2019. Red symbols depict negative effects, and blue symbols depict positive effects. Significant results are marked with asterisks (*** indicates $p$-value $<0.001$ )

et al. 2015; Takekawa et al. 2017). This diversity of migration patterns underlines the need to apply telemetry studies to more Bar-headed Geese marked throughout their breeding distribution to enable us to better delineate the flyway structure of this species, which remains poorly known, and to ensure adequate site safeguard for geese of different breeding provenance. Such an understanding is essential if we are to be able to appraise the effectiveness of the cohesive site-safeguard network to protect all the elements of this complex population throughout its annual cycle. This is especially important because the species exploits arid and high altitude ecosystems at different times of its annual cycle, all of which are known to be particularly susceptible to the effects of current on-going climate change. For example, effects of climate change at one of the Bar-headed Goose's major breeding sites in west Mongolia, which has experienced the most rapid rise in temperatures in the past decade outside of the Arctic regions (Batbayar et al. 2014), may have serious impacts on their breeding success. In the QTP, the extent of wetlands have increased in the eastern part and decreased in the western-central sectors (Xu et al. 2019), factors which may explain increases in breeding Barheaded Geese in this area relative to numbers in Mongolia. On the other hand, in TAR, the species is considered to be more vulnerable to power line strikes ( $\mathrm{Li}$ et al. 2011) and avian influenza (Liu et al. 2010).

The results from this analysis of habitat use by Barheaded Geese reflect those of many northern hemisphere goose species, which typically feed out in wetlands and grassland by day but resort to open water bodies by night as protection from potential predators (Zhao 2017). Bar-headed Geese mainly used natural ecosystems during migration and on the summering areas, but cropland during winter. In summer, $35 \%$ of positional fixes from tagged geese captured at Qinghai Lake were from grassland and 54\% from wetlands during the breeding and post-breeding period (Prosser et al. 2011). Zheng et al. (2018) reported 53\% of positional fixes from their telemetry tracked Bar-headed Geese were from wetland, 21\% 
forest and $18 \%$ bare substrate in Qinghai Lake $(n=8)$. We found very low forest cover when overlaying the home ranges from Zheng et al. (2018) on the ESA Global Cover 2009 maps and goose use of forest habitats seems extremely unlikely.

During migration, geese mainly used grassland, water bodies, wetlands and bare substrates at their stopover sites in our study. Prosser et al. (2011) reported $75 \%$ of positions of tagged Bar-headed Geese came from grassland and $>12 \%$ from wetlands during autumn and spring migration. Both studies therefore confirmed tagged geese mainly used natural ecosystems during migration. Small differences between our and Prosser et al's (2011) results may be the consequence of land-cover changes that have affected goose habitat availability in the last two decades and improvements in accuracy of the land cover dataset. Prosser et al. (2011) used the 2003 dataset based on $1 \mathrm{~km}$ resolution, whereas our study used the 2019 dataset with $10 \mathrm{~m}$ accuracy.

During winter, geese mainly used winter wheat fields, or fallow croplands, rivers, lakes and marshes along the Yarlung Zangbo River. Ground counts of feeding geese $(n=44,657$ in January 2009) found $72.1 \%$ on fallow cropland (Liu et al. 2010). Prosser et al. (2011) also reported tagged geese used 39\% cropland near Lhasa city. In addition, Bar-headed Geese also used grassland and cropland as their main diurnal feeding areas at Caohai, China (Yang et al. 2013), Lashihai Lakes, China (Yan et al. 2014) and Keoladeo National Park, India (Middleton and Van der Valk 1987). Hence, like many northern hemisphere goose species, the Bar-headed Goose has shown a plasticity that has enabled it to take advantage of the new farmland feeding opportunities on the wintering areas (Fox and Abraham 2017). We speculate that restricted use of croplands in summer and on migration simply reflects the general remoteness of the areas that they use at these stages of the life cycle, in regions where the area of cropland available for foraging is extremely restricted.

In our original GLMM modelling to compare the habitat types used by geese with pseudo-absence measures in the immediate vicinity, we also entered water recurrence (Pekel et al. 2016) as a potential explanatory parameter, but it was highly correlated with "water body". Deletion of water recurrence from the model resulted in an AUC of more than 0.7 , indicating reasonable predictions from this simplified model. In our final model, geese tended to select wetland and water bodies as habitat, because the seasonal growth of aquatic plants provides accessible digestible biomass which can be exploited to accumulate fat stores by day (Cong et al. 2012; Wang et al. 2013), and open water offers a night time roosting refuge to avoid predators. Geese also appeared to prefer south facing stopover sites, probably because these areas gain maximum solar insolation to stimulate the growth of food plants to support fat accumulation during the spring migration and shelter from the north wind during the autumn migration. Geese avoided bare substrates strongly in spring, probably because of the low surface temperatures and frost during spring migration in these areas. Summering Bar-headed Geese at Qinghai Lake preferred wetland, open land with sparse vegetation, sites close to rivers/lakes and away from roads, croplands and higher elevations (Zheng et al. 2018) and we contest that they also avoided forest. Wintering Bar-headed Geese at Caohai Lake showed a preference for sites with high vegetation cover, low vegetation height, far from human disturbance, close to the water, open habitats and lower elevation as their foraging sites (Yang et al. 2013). Our results closely followed theirs, confirming that all stages of the life cycle, Bar-headed Geese tend to select wetland areas, close to rivers/lakes, away from roads and at lower elevations than would be expected by chance.

The habitat selection patterns of Bar-headed Geese also reflect patterns shown by Greylag Geese in their breeding and wintering areas in East China (Li 2019). Both species tend to select water bodies and wetland as habitat, although Greylag Geese occur in sites nearer to roads and tend to show greater selection for cropland, suggesting they are more tolerant of human disturbance than Bar-headed Geese. Cropland was not used as a parameter in our model, because it contributed only $1 \%$ to habitat use among tagged Bar-headed Geese. In conclusion, these results, together with the results of previous studies of the species, continue to indicate that Bar-headed Geese rely predominantly on wetland and water bodies during migration staging in the QTP in the absence of major human impacts on the landscape in these areas.

In contrast, increasing numbers of Bar-headed Geese are shifting to croplands during the winter. This is especially evident along the Yarlung Zangbo River (where the area of cropland increased by $15.5 \%$ between 1990 and 2015; Wu et al. 2017). Numbers of Bar-headed Geese wintering along the Yarlung Zangbo River rose from 15,000 in the 1990s (Bishop et al. 1997) to 30,000 in 2007 (Bishop and Tsamchu 2007) to 67,000 in 2014 (Liu et al. 2017) as increasing numbers resorted to farmland to feed.

The Qinghai-Tibet Plateau is a vast territory with high biodiversity interest and a sparse human population, which has benefitted from the positive effects of nature conservation designation, particularly evident through the current large extent of protected areas. Relatively high levels of site protection for the Greylag Geese in East China have resulted in that species spending more than $65 \%$ of their stopover duration within IBA/protected areas during migration, and their population size 
is increasing ( $\mathrm{Li}$ et al. 2020), suggesting that site protection can contribute to supporting increasing numbers of geese over time. It would therefore appear that Barheaded Geese have benefitted from improved conservation action (especially protected areas designation) at migration stopovers en route to and from their breeding areas, as well as from the increasing use of energy rich agriculture areas as winter quarters. Nevertheless, as we identify above, with climate change imposing spatially explicit patterns of change in different parts of the annual range of the Bar-headed Goose, it remains essential we improve our understanding of their migration routes and flyways through extended telemetry studies and monitor their population dynamics and abundance to ensure the future of this unique Asian goose species.

\section{Conclusions}

This study is the first to identify the paramount importance of stopover sites within the QTP to Bar-headed Geese in their annual cycle, but also to confirm the satisfactory level of current site protection given the patterns revealed by our telemetry data, which is consistent with the upward trend in abundance of the ETF Bar-headed Goose. We recommend Hala Lake and adjacent areas for protection because of their disproportionate importance to the geese during the initial stages of their autumn migration, which are currently outside the present network of NNRs/IBAs. Bar-headed Geese mainly used natural ecosystems during migratory stopovers (the majority feeding on grasslands by daytime and roosting on water body at night). Habitat modelling confirmed geese tend to select wetland areas, close to rivers/lakes, away from roads and at lower elevations.

\section{Supplementary information}

Supplementary information accompanies this paper at https://doi. org/10.1186/s40657-020-00230-9.

Additional file 1: Figure S1. Map showing the nature and extent of the two distinctive flyways of the Bar-headed Goose (Anser indicus) in Central Asia.

Additional file 2: Table S1. Summary table of Bar-headed Geese (Anser indicus) fitted with solar-powered GPS/GSM telemetry devices in the current analysis. Table S2. The location and duration of stopover sites in the Qinghai-Tibet Plateau used by tracked Bar-headed Geese $(n=17)$ during autumn migration in 2016 and 2018. Table S3. The location and duration of stopover sites in the Qinghai-Tibet Plateau used by tracked Bar-headed Geese $(n=8)$ during spring migration in 2019. Table S4. Conservation status of Bar-headed Geese stopovers in the Qinghai-Tibet Plateau during autumn and spring migration. Table S5. Parameter estimates ( $\beta$ ), standard errors, $p$ values, and $95 \%$ confidence limits from the highest-ranked model (Table 2) estimating habitat selection of Bar-headed Geese in stopovers within the Qinghai-Tibet Plateau during autumn migration. Table S6. Parameter estimates ( $\beta$ ), standard errors, $p$ values, and $95 \%$ confidence limits from the highest-ranked model (Table 2) estimating habitat selection of Bar-headed Geese in stopovers within the Qinghai-Tibet Plateau during spring migration.

\section{Acknowledgments}

We gratefully acknowledge the contribution of Xin Wang and Xianghuang Li for their help on data analysis, and Ming Ma for his help on the Bar-headed Goose distribution in the Xinjiang Uygur Autonomous Region, China. We are also indebted to the anonymous reviewers for their constructive comments and suggestions that greatly improve the manuscript.

\section{Authors' contributions}

$L C, J Z, Y X$ and ADF conceived the ideas and designed methodology; LL, NB, ID and FM collected the data; JZ and XD analyzed the data. JZ led the writing of the manuscript, with contributions from LC, YX and ADF. All authors contributed critically to the drafts and gave final approval for publication. All authors read and approved the final manuscript.

\section{Funding}

Our study was supported by the National Natural Science Foundation of China (Grant No. 31870369 \& No. 31970433 \& No. 31670424) and China Biodiversity Observation Networks (Sino BON). The funders had no role in study design, data collection and analysis, decision to publish, or preparation of the manuscript.

\section{Availability of data and materials}

The datasets used in the present study are available from the corresponding author on reasonable request.

\section{Ethical approval and consent to participate}

The following information was supplied relating to ethical approvals (i.e., approving body and any reference numbers): The Animal Ethics Committee, Research for Eco-Environmental Sciences, Chinese Academy of Sciences fully approved this study. Approval for bird capture and transmitter deployment in Mongolia was obtained from the Ministry of Nature, Environmental and Tourism of Mongolia (permission number: No 06/2862). Approval for transmitter deployment at Qinghai Lake, China was obtained from the Qinghai Lake National Nature Reserve authorities.

\section{Consent for publication}

Not applicable.

\section{Competing interests}

The authors declare that they have no competing interests.

\section{Author details}

1 State Key Laboratory of Urban and Regional Ecology, Research Center for Eco-Environmental Sciences, Chinese Academy of Sciences, Beijing 100085, China. ${ }^{2}$ University of Chinese Academy of Sciences, Beijing 100049, China. ${ }^{3}$ Department of Modern Physics, University of Science and Technology of China, Hefei 230026, China. ${ }^{4}$ Northwest Institute of Plateau Biology, Chinese Academy of Sciences, Xining 810008, China. ${ }^{5}$ Wild life Science and Conservation Center, B-802 Union Building, Sukhbaatar District, Ulaanbaatar 14210, Mongolia. ${ }^{6}$ Institute of Biology, Mongolian Academy of Sciences, Ulaanbaatar 13330, Mongolia. ${ }^{7}$ Department of Bioscience, Aarhus University, Kalø, Grenåvej 14, DK-8410 Rønde, Denmark.

Received: 22 May 2020 Accepted: 27 October 2020

Published online: 08 December 2020

\section{References}

Altman M, Gill J, McDonald MP. Numerical issues in statistical computing for the social scientist. Hoboken, New Jersey: Wiley; 2004.

Bartoń K. MuMln: Multi-model inference. R package version 1.43.15. 2019. https://CRAN.R-project.org/package=MuMIn.

Batbayar N, Takekawa JY, Natsagdorj T, Spragens KA, Xiao X. Site selection and nest survival of the Bar-headed Goose (Anser indicus) on the Mongolian Plateau. Waterbirds. 2014;37:381-93. 
Becker RA, Chambers JM. S: An interactive environment for data analysis and graphics. Boca Raton: CRC Press; 1984.

BirdLife International. Country profile: China (mainland). 2020. https://www. birdlife.org/datazone/country/china. Accessed 07 Jan 2020.

Bishop CM, Spivey RJ, Hawkes LA, Batbayar N, Chua B, Frappell PB, et al. The roller coaster flight strategy of bar-headed geese conserves energy during Himalayan migrations. Science. 2015;347:250-4.

Bishop MA, Tsamchu D. Tibet Autonomous region january 2007 survey for Black-necked crane, Common crane, and Bar-headed goose. China Crane News. 2007;11:24-6.

Bishop MA, Yanling S, Zhouma C, Binyuan G. Bar-headed Geese Anser indicus wintering in south-central Tibet. Wildfowl. 1997;48:118-26.

Block WM, Brennan LA. The habitat concept in ornithology. In: Power DM, editor. Current ornithology. Berlin: Springer; 1993. p. 35-91.

Bodey TW, Cleasby IR, Bell F, Parr N, Schultz A, Votier SC, et al. A phylogenetically controlled meta-analysis of biologging device effects on birds: deleterious effects and a call for more standardized reporting of study data. Methods Ecol Evol. 2018;9:946-55.

Bourouiba L, Wu J, Newman S, Takekawa J, Natdorj T, Batbayar N, et al. Spatial dynamics of bar-headed geese migration in the context of H5N1. J R Soc Interface. 2010;7:1627-39.

Chen H, Li Y, Li Z, Shi J, Shinya K, Deng G, et al. Properties and dissemination of $\mathrm{H} 5 \mathrm{~N} 1$ viruses isolated during an influenza outbreak in migratory waterfowl in western China. JVirol. 2006;80:5976-83.

Chen W, Doko T, Fujita G, Hijikata N, Tokita K-I, Uchida K, et al. Migration of tundra swans (Cygnus columbianus) wintering in Japan using satellite tracking: identification of the Eastern Palearctic flyway. Zool Sci. 2016;33:63-72.

Cong P, Wang X, Cao L, Fox AD. Within-winter shifts in Lesser White-fronted Goose Anser erythropus distribution at East Dongting Lake, China. Ardea. 2012;100:5-11.

Cui P, Hou Y, Tang M, Zhang H, Zhou Y, Yin Z, et al. Movement patterns of Barheaded Geese Anser indicus during breeding and post-breeding periods at Qinghai Lake, China. J Ornithol. 2011;152:83-92.

Fox AD, Abraham KF. Why geese benefit from the transition from natural vegetation to agriculture. Ambio. 2017;46:188-97.

Fox AD, Leafloor JO. A global audit of the status and trends of Arctic and Northern Hemisphere goose populations. Akureyri: Conservation of Arctic Flora and Fauna International Secretariat; 2018.

Gong P, Liu H, Zhang M, Li C, Wang J, Huang H, et al. Stable classification with limited sample: transferring a 30-m resolution sample set collected in 2015 to mapping 10-m resolution global land cover in 2017. Sci Bull. 2019;64:370-3.

Gong P, Wang J, Yu L, Zhao Y, Zhao Y, Liang L, et al. Finer resolution observation and monitoring of global land cover: first mapping results with Landsat TM and ETM+ data. Int J Remote Sens. 2013;34:2607-54.

Hao M, Zhang Y, Lei F, Yan B, Xing Z. Potential habitat analysis of Anser indicus with digital elevation model. Chin J Zool. 2010;45:35-42 (In Chinese).

Hawkes L, Batbayar N, Bishop C, Butler PJ, Frappell P, Meir JU, et al. Goose migration over the Himalayas: Physiological adaptations. In: Prins HHT, Namgail T, editors., Bird migration across the Himalayas: Wetland functioning amidst mountains and glaciers. Cambridge: Cambridge University Press; 2017. p. 241-53.

Hawkes LA, Balachandran S, Batbayar N, Butler PJ, Frappell PB, Milsom WK, et al. The trans-Himalayan flights of bar-headed geese (Anser indicus). P Natl Acad Sci USA. 2011;108:9516-9.

Hawkes LA, Balachandran S, Batbayar N, Butler PJ, Chua B, Douglas DC, et al. The paradox of extreme high-altitude migration in bar-headed geese Anser indicus. P Roy Soc B-Biol Sci. 2013;280:20122114.

Hosmer DW Jr, Lemeshow S, Sturdivant RX. Applied logistic regression. 3rd ed. Hoboken, New Jersey: John Wiley \& Sons; 2013.

Jones J. Habitat selection studies in avian ecology: a critical review. Auk. 2001;118:557-62.

Kölzsch A, Müskens GJ, Kruckenberg H, Glazov P, Weinzierl R, Nolet BA, et al. Towards a new understanding of migration timing: slower spring than autumn migration in geese reflects different decision rules for stopover use and departure. Oikos. 2016;125:1496-507.

Köppen U, Yakovlev AP, Barth R, Kaatz M, Berthold P. Seasonal migrations of four individual bar-headed geese Anser indicus from Kyrgyzstan followed by satellite telemetry. J Ornithol. 2010;151:703-12.

Li F, Bishop MA, Drolma T. Power line strikes by black-necked cranes and barheaded geese in Tibet Autonomous Region. Chin Birds. 2011;2:167-73.
Li X. Annual migratory patterns of Greylag Geese (Anser anser rubrirostris) revealed by satellite tracking. Master's Thesis. Beijing: University of Chinese Academy of Sciences; 2019 (In Chinese).

Li X, Wang X, Fang L, Batbayar N, Natsagdorj T, Davaasuren B, et al. Annual migratory patterns of Mongolian-Manchurian Eastern Greylag Geese (Anser anser rubrirostris) revealed by GPS/GSM loggers. Integr Zool. 2020;15:213-23.

Li ZWD, Bloem A, Delany S, Martakis G, Quintero JO. Status of waterbirds in Asia-Results of the Asian Waterbird Census: 1987-2007. Kuala Lumpur, Malaysia: Wetlands International; 2009.

Liu D, Zhang G, Li F, Ma T, Lu J, Qian F. A revised species population estimate for the Bar-headed Goose (Anser indicus). Avian Res. 2017;8:7.

Liu D, Zhang G, Jiang H, Shan K, Hou Y-Q, Dai M, et al. Movement and habitat utilization of breeding Bar-headed Goose and the relationship with humans in Qinghai Lake. Acta Ecol Sin. 2008;28:5201-8 (In Chinese).

Liu D, Zhang G, Qian F, Hou Y, Dai M, Jiang H, et al. Population, distribution and home range of wintering bar-headed goose along Yarlung Zangbo River,\&nbsp;Tibet. Acta Ecol Sin. 2010;30:4173-9 (In Chinese).

Meng F, Wang X, Batbayar N, Natsagdorj T, Davaasuren B, Damba I, et al. Consistent habitat preference underpins the geographically divergent autumn migration of individual Mongolian common shelducks. Curr Zool. 2020. https://doi.org/10.1093/cz/zoz056.

Middleton BA. Habitat and food preferences of Greylag and Barheaded Geese wintering in the Keoladeo National Park. India J Trop Ecol. 1992;8:181-93.

Middleton BA, Van der Valk AG. The food habits of Greylag and Barheaded Geese in the Keoladeo National Park. India Wildfowl. 1987;38:94-102.

Millspaugh JJ, Marzluff JM. Radio-tracking and animal populations: past trends and future needs. In: Millspaugh JJ, Marzluff JM, editors. Radio tracking and animal populations. San Diego: Academic Press; 2001. p. 383-93.

Newman SH, Hill NJ, Spragens KA, Janies D, Voronkin IO, Prosser DJ, et al. Eco-virological approach for assessing the role of wild birds in the spread of avian influenza H5N1 along the Central Asian Flyway. PLoS ONE. 2012; 7:e30636.

Northrup JM, Hooten MB, Anderson CR Jr, Wittemyer G. Practical guidance on characterizing availability in resource selection functions under a useavailability design. Ecology. 2013;94:1456-63.

Page GW, Warnock N, Tibbitts TL, Jorgensen D, Hartman CA, Stenzel LE. Annual migratory patterns of Long-billed Curlews in the American West. Condor. 2014;116:50-61.

Pekel J-F, Cottam A, Gorelick N, Belward AS. High-resolution mapping of global surface water and its long-term changes. Nature. 2016;540:418-22.

Prins HHT, van Wieren SE. Number, population structure and habitat use of bar-headed geese Anser indicus in Ladakh (India) during the broodrearing period. Acta Zool Sin. 2004;50:738-44.

Prosser DJ, Takekawa JY, Newman SH, Yan B, Douglas DC, Hou Y, et al. Satellitemarked waterfowl reveal migratory connection between $\mathrm{H} 5 \mathrm{~N} 1$ outbreak areas in China and Mongolia. Ibis. 2009;151:568-76.

Prosser DJ, Cui P, Takekawa JY, Tang M, Hou Y, Collins BM, et al. Wild bird migration across the Qinghai-Tibetan plateau: a transmission route for highly pathogenic H5N1. PLOS ONE. 2011;6:e17622.

R Core Team. R: A language and environment for statistical computing. Vienna, Austria: R Foundation for Statistical Computing; 2019. https://www.Rproject.org/.

Signer J, Fieberg J, Avgar T. Animal movement tools (amt): R package for managing tracking data and conducting habitat selection analyses. Ecol Evol. 2019;9:880-90.

Szumilas M. Explaining odds ratios. J Can Acad Child Adol Psy. 2010;19:227-9.

Takekawa J, Heath SR, Douglas DC, Perry WM, Javed S, Newman SH, et al. Geographic variation in Bar-headed Geese Anser indicus: connectivity of wintering areas and breeding grounds across a broad front. Wildfowl. 2009;59:100-23.

Takekawa JY, Palm EC, Prosser DJ, Hawkes LA, Batbayar N, Balachandran S, et al. Goose migration across the Himalayas: Migratory routes and movement patterns of Bar-headed Geese. In: Prins HHT, Namgail T, editors. Bird migration across the Himalayas: Wetland functioning amidst mountains and glaciers. Cambridge: Cambridge University Press; 2017. p. 15-29.

Tian H, Zhou S, Dong L, Van Boeckel TP, Cui Y, Wu Y, et al. Avian influenza H5N1 viral and bird migration networks in Asia. P Natl Acad Sci USA. 2015;112:172-7.

Van der Ven J, Gole P, Ouweneel G. Bar-headed Geese Anser indicus: Notes from breeding and wintering areas. Goose Bull. 2010;10:7-17. 
Wang X, Fox AD, Cong PH, Cao L. Food constraints explain the restricted distribution of wintering Lesser White-fronted Geese Anser erythropus in China. Ibis. 2013;155:576-92.

Wang X, Cao L, Bysykatova I, Xu Z, Rozenfeld S, Jeong W, et al. The Far East taiga forest unrecognized inhospitable terrain for migrating Arctic-nesting waterbirds? PeerJ. 2018;6:e4353.

Wu B, Qian J, Zeng Y, Zhang L, Yan C, Wang Z, et al. Land cover atlas of the People's Republic of China (1: 1,000,000). Beijing: China Map Publishing House; 2017. (In Chinese).

Wutzler T. Solartime: Utilities dealing with solar time such as sun position and time of sunrise. R package version 0.0.1. 2018. https://CRAN.R-project.org/ package $=$ solartime.

Xu W, Fan X, Ma J, Pimm SL, Kong L, Zeng Y, et al. Hidden loss of wetlands in China. Curr Biol. 2019;29:3065-71.

Xu Y, Si Y, Takekawa J, Liu Q, Prins HHT, Yin S, et al. A network approach to prioritize conservation efforts for migratory birds. Conserv Biol. 2020;34:416-26.

Yan L, Hu M, Meng F, Liu N. Foraging habitat selection of Anser indicus during winter at Lashihai Lake in Yunnan Province. Mod Agr Sci Tech. 2014;10:164 (In Chinese)

Yang F. Report on a three year survey of Black-necked Crane and large-sized waterbirds on the Yunnan and Guizhou Plateau. In: Li F, Yang X, Yang F, editors. Status and conservation of Black-necked Cranes on the Yunnan and Guizhou Plateau, People's Republic of China. Kunming: Yunnan Nationality Publishing House; 2005. p. 59-64 (In Chinese).

Yang F, Zhang YQ. Quantities and distribution of the Black-necked Crane (Grus nigricollis) and other large waterfowl on the Yunnan and Guizhou Plateau. Zool Res. 2014;35:80-4.

Yang Y, Zhang G, Lu J, Liu W, Li Z. Diurnal activity patterns and environmental factors on behaviors of Bar-headed Geese Anser indicus wintering at Caohai Lake of Guizhou, China. Acta Ecol Sin. 2012:32:7280-8 (In Chinese).

Yang Y, Zhang G, Lu J, Liu W, Li Z. Foraging habitat selection of Bar-headed Goose in winter at Caohai National Reserve in Guizhou. Sci Silvae Sin. 2013:49:176-80 (In Chinese).

Ydenberg RC. The Himalayas as an ecological barrier for avian migrants: High and dry, but also dangerous? In: Prins HHT, Namgail T, editors. Bird migration across the Himalayas: Wetland functioning amidst mountains and glaciers. Cambridge: Cambridge University Press; 2017. p. 283.

Zhang G, Liu D, Qian F, Jiang H, Hou Y, Dai M. Diversity of waterbirds and change in home range of bar-headed geese Anser indicus during breeding period at Hangcuo Lake of Tibet, China. Acta Ecol Sin. 2011a;31:395400 (In Chinese).

Zhang GG, Liu DP, Hou YQ, Jiang HX, Dai M, Qian FW, et al. Migration routes and stop-over sites determined with satellite tracking of bar-headed geese Anser indicus breeding at Qinghai Lake, China. Waterbirds. 2011b;34:112-6.

Zhang G, Liu D, Qian F, Hou Y, Chen L, Dai Q, et al. The water bird community and home range of the bar-headed goose at Yamdrok Lake in Tibet, China. Acta Ecol Sin. 2016;36:946-52 (In Chinese).

Zhao M. Wintering ecology and population trend of Anseriformes in the middle and lower Yangtze River floodplain. PhD Thesis. Hefei: University of Science and Technology of China; 2017 (In Chinese).

Zheng R, Smith LM, Prosser DJ, Takekawa JY, Newman SH, Sullivan JD, et al. Investigating home range, movement pattern, and habitat selection of Bar-headed Geese during breeding season at Qinghai Lake, China. Animals. 2018;8:182.
Ready to submit your research? Choose BMC and benefit from:

- fast, convenient online submission

- thorough peer review by experienced researchers in your field

- rapid publication on acceptance

- support for research data, including large and complex data types

- gold Open Access which fosters wider collaboration and increased citations

- maximum visibility for your research: over 100M website views per year

At BMC, research is always in progress.

Learn more biomedcentral.com/submissions 